\title{
THE EFFECT OF CANOPY DEVELOPMENT AND SPRAYER POSITION ON SPRAY DRIFT FROM A PIPFRUIT ORCHARD
}

\author{
J.-P. PRAAT ${ }^{1}$, J.F. MABER ${ }^{1}$ and D.W.L. MANKTELOW ${ }^{2}$ \\ ${ }^{1}$ Lincoln Ventures Ltd, Ruakura Research Centre, Private Bag 3062, Hamilton \\ ${ }^{2}$ HortResearch, Hawke's Bay Research Centre, Private Bag 1401, Havelock North
}

\begin{abstract}
Spray drift continues to be an important issue for commercial pipfruit growers. Off-target agrichemical movement was determined from the Hawke's Bay Focus Orchard on two occasions. Canopy development had a major influence on spray drift, with 25 times less drift from a fully foliated canopy compared with a dormant canopy. The proximity of the sprayer relative to the edge of the sprayed block was an additional major factor influencing spray drift. Results are compared with those found in previous New Zealand and overseas studies and management strategies for spray drift minimisation are discussed.
\end{abstract}

Keywords: spray drift, drift management, pipfruit, canopy development, sprayer operation.

\section{INTRODUCTION}

Agrichemical spray drift is an emotive issue. While it is impossible to guarantee that no pesticide movement will occur beyond sprayed areas, e.g. through volatilisation off sprayed foliage, it is important to establish objective assessments for drift risks under different orchard and weather conditions. It is also important to relate potential spray drift levels to possible risks of environmental damage, human health problems or crop damage/contamination. The Resource Management Act has lead to Regional Councils introducing specific rules in their regional air plans to limit spray drift. To a certain extent growers of fresh produce have been prepared for this with the wide adoption of the GROWSAFE ${ }^{\circledR}$ Certification scheme for agrichemical use. Some detailed information on spray drift from orchards has been published (Holland et al. 1997). However, there is a lack of published information on spray drift specific to New Zealand pipfruit orchards from which sound judgements can be made as to the risk spray drift may pose. Many factors influence risks associated with spray drift, most importantly, droplet size, meteorological conditions during spraying and pesticide toxicity. Those making spray applications have the greatest influence on the impact of spray drift on areas surrounding application but may not have sufficient information at the time of spraying to minimise spray drift.

This paper describes two trials carried out on a Hawke's Bay apple orchard in 1999 , to determine the effects of canopy development and sprayer operation on spray drift. Comparison of sampling techniques, strategies for managing spray drift risk and risk assessments are discussed.

\section{METHODS}

Two drift assessment trials were conducted in 1999, the first on 23 September when trees had effectively no leaf cover (dormant) and the second on 17 December when trees were fully foliated. The same block of Braeburn apples on the Hawke's Bay Focus Orchard, Rakanui block was used in each assessment. This 1.7 ha block consisted of 15 rows of mature slender pyramid trees, planted at $4.5 \mathrm{~m}$ between rows and $2.5 \mathrm{~m}$ along rows. Tree form within the block was very regular, with a maximum height of ca $4.5 \mathrm{~m}$. The height-stratified-tree-row-volume (Manktelow and Praat 1997) as measured in August 1999 was 22,000 m³/ha. 


\section{Spray application}

Two typical commercial spray applications were monitored. Spraying was carried out using a Cropliner airblast sprayer, fitted with a $920 \mathrm{~mm}$ axial fan without straightening vanes. Volume application rates were 500 and 2000 litres/ha for dormant and full foliage applications respectively. These treatments are comparable as variations in volume application rates in this range have previously been shown not to influence spray drift (Holland et al. 1997). Groups of three rows were sprayed sequentially starting with the outside three rows, followed by rows four to six and so on. The outside row was sprayed from both sides. A least 1 ha was sprayed during the trial for at least $100 \mathrm{~m}$ either side of the sampling line (Fig. 1). Wind speed and direction remained relatively stable during spraying for both trials so that the quantity of drift recovered was comparable. Myclobutinal (Systhane $40 \mathrm{~W}$ ) and diazinon (Basudin 50 WP) were applied for dormant and full foliage treatments respectively at recommended label rates. Resulting application rates were $0.068 \mathrm{~kg} / \mathrm{ha}$ myclobutanil and $1 \mathrm{~kg} / \mathrm{ha}$ diazinon.

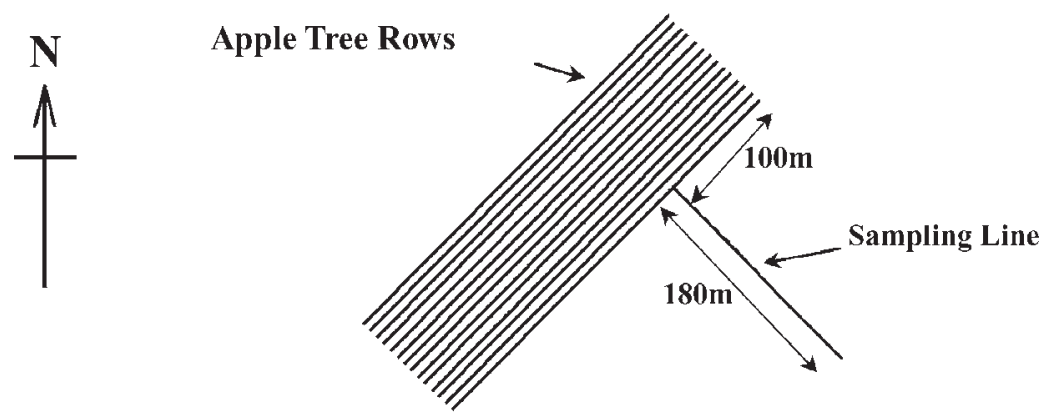

FIGURE 1: Schematic layout of apple orchard and sampling line.

\section{Spray drift monitoring}

Soil deposit samplers were placed horizontally on the ground and laid out perpendicular to and downwind from the sprayed block at 7.6, 15, 30, 90 and $180 \mathrm{~m}$ from the edge of the sprayed orchard (Fig. 1). The edge of the sprayed block was taken as $4.5 \mathrm{~m}$ from the trunkline of the outside row of trees. There was no shelter at the edge of the sprayed block. Soil deposits were collected on either chromotography paper (1 Chr, Whatman Cat No 3001 917, $0.17 \mathrm{~mm}$ thick) or alpha-cellulose sheet (a cotton by-product, $1.2 \mathrm{~mm}$ thick). The alpha-cellulose sheet was included in the trials as this material was used by the Spray Drift Task Force (SDTF) in the United States (Johnson 1997). The chromatography paper was fixed on a tin foil and cardboard backing and the alpha-cellulose on a backing of alpha-cellulose. Immediately after the sampling period each collector was removed from the backing and placed in a glass bottle with $50 \mathrm{ml}$ acetone. Three soil deposit samplers were located at each distance from the sprayed block. Aerial drift samplers were placed $2 \mathrm{~m}$ above the ground at the 15,30 and $90 \mathrm{~m}$ sampling stations. A further sampler was located at $10 \mathrm{~m}$ above the ground at the $15 \mathrm{~m}$ station. Aerial drift (aerosol and vapour) was trapped using the method described by Holland (1997). All samples were placed in cool storage after sampling. Quantitative analysis of agrichemical trapped by samplers was carried out using the method described in Holland et al. (1997). The results are expressed per unit ground area $\left(\mu \mathrm{g} / \mathrm{m}^{2}\right)$, as a percentage of applied spray for deposited drift and per unit volume $\left(\mu \mathrm{g} / \mathrm{m}^{3}\right)$ for aerial drift (aerosol and vapour). Samples taken before the spray event established background agrichemical levels of $2 \mathrm{mg} / \mathrm{m}^{2}$ for soil deposits for both trials and $0.06 \mathrm{mg} / \mathrm{m}^{3}$ for aerial drift in the full foliage trial. Weather conditions, including wind speed and direction, temperatures at 2, 5 and $10 \mathrm{~m}$ above ground and relative humidity, were recorded at 1 min intervals during the trial period. 


\section{Weather conditions}

\section{RESULTS AND DISCUSSION}

Table 1 shows the weather data recorded during the two trials. Winds were light on both occasions. Wind direction varied from blowing directly toward samplers while the first three rows were sprayed to tending down the rows for the full foliage trial. Mean air temperatures were higher for the full foliage trial while relative humidity was similar for both trials. The length of the sprayed block (at least $100 \mathrm{~m}$ ) was such that even though the wind did not always blow directly toward the samplers valid results were still obtained.

TABLE 1: Wind speed, wind direction and air temperature recorded during two spray drift trials.

\begin{tabular}{|c|c|c|c|c|c|}
\hline $\begin{array}{l}\text { Canopy } \\
\text { development }\end{array}$ & Time & $\begin{array}{l}\text { Temperature } \\
\left({ }^{\circ} \mathrm{C}, 2 \mathrm{~m}\right. \\
\text { above ground) }\end{array}$ & $\begin{array}{c}\text { Relative } \\
\text { humidity } \\
(\%)\end{array}$ & $\begin{array}{l}\text { Wind speed } \\
(\mathrm{m} / \mathrm{s})\end{array}$ & Direction \\
\hline Dormant & $08: 13$ to $10: 02$ & 9 to 13 & 64 to $79^{1}$ & 1.0 to 1.2 & From sou'west \\
\hline Full Foliage & $08: 13$ to $10: 45$ & 18 to 21 & 72 to $79^{1}$ & 0.5 to $2.8^{2}$ & Variable \\
\hline
\end{tabular}

${ }^{1}$ Higher humidity at the beginning of the trial.

${ }^{2}$ Wind speed was 0.5 to $1.5 \mathrm{~m} / \mathrm{s}$ during spraying of rows 1 to 9 and increased to 2.8 $\mathrm{m} / \mathrm{s}$ during spraying of row 10 inwards.

\section{Soil Deposition}

The quantity of soil deposit collected using each sampler type is shown in Table 2. The US samplers were thicker and had a rougher surface than the chromotography paper (NZ) samplers but were not different $(\mathrm{P}>0.05)$ in the mean quantity of soil deposits detected. Therefore soil deposit data from three samplers at each distance were combined.

TABLE 2: Mean amounts of agrichemical detected in different types of samplers at 15 to $180 \mathrm{~m}$ positions inclusive in two spray drift trials with dormant or full foliage development.

\begin{tabular}{lcccc}
\hline & \multicolumn{4}{c}{ Canopy development } \\
Sampler type (size) & $\begin{array}{c}\text { Dormant } \\
\mu \mathrm{g} / \mathrm{m}^{3}\end{array} \%$ of applied & $\begin{array}{c}\text { Full foliage } \\
\mu \mathrm{g} / \mathrm{m}^{3} \%\end{array}$ of applied \\
\hline $\begin{array}{l}\text { Alpha-cellulose (US) }(15.8 \times 15.8 \mathrm{~cm}) \\
\begin{array}{l}\text { Chromotograhpy paper (NZL) } \\
(23.5 \times 28 \mathrm{~cm})\end{array}\end{array}$ & 91 & 1.3382 & 74 & 0.0740 \\
$\begin{array}{l}\text { Chromotograhpy paper (NZS) } \\
(20 \times 20 \mathrm{~cm})\end{array}$ & 131 & 1.9265 & 63 & 0.0630 \\
\hline
\end{tabular}

Table 3 describes the effect of canopy development and distance on the quantity of spray drift deposited on the soil. On average there was a 25 -fold reduction in the amount of spray drift when leaves were present on trees than when dormant trees were sprayed. Similar studies in the US recorded a 35-fold reduction in spray drift (Johnson 1997). Live foliated trees were good at intercepting spray. The spray which is not retained by the crop is likely to pass over the top, underneath and between trees. Conventional airblast sprayers can be adjusted to reduce the likelihood of spray escaping above or below canopies but it is more difficult to control the spray going through the gaps between trees. Sprayers with sensor controlled nozzles are available which can detect gaps between trees and shut off nozzles as appropriate (Perry 1995; Koch and Weisser 2000). These sensor-controlled sprayers reduce spray drift, 
especially early in the season, and also reduce the quantity of active ingredient used in comparison with conventional sprayers.

TABLE 3: Mean amounts of agrichemical soil deposits detected in samplers at different distances from a sprayed orchard block in two spray drift trials with dormant or full foliage development.

\begin{tabular}{|c|c|c|c|c|c|}
\hline \multirow[t]{2}{*}{ Canopy development } & \multicolumn{5}{|c|}{ Distance from edge of sprayed block (m) } \\
\hline & 7.6 & 15 & 30 & 90 & 180 \\
\hline & \multicolumn{5}{|c|}{ Soil deposits $\left(\mathrm{mg} / \mathrm{m}^{2}\right)$} \\
\hline Dormant & 1212 & 376 & 94 & 1.1 & 0.7 \\
\hline Full foliage & 1953 & 188 & 16 & 12 & 2.5 \\
\hline \multicolumn{6}{|c|}{ Soil deposits (\% of applied) } \\
\hline Dormant & 17.8235 & 5.5294 & 1.3824 & 0.0162 & 0.0103 \\
\hline Full foliage & 1.9530 & 0.1880 & 0.0160 & 0.0120 & 0.0025 \\
\hline
\end{tabular}

Figs 2 and 3 show the effect of sprayer position on spray deposited outside the sprayed block for dormant and foliated apple orchards respectively. As the sprayer was operated at greater distances from the edge of the sprayed block, spray drift was drastically reduced. During the dormant trial, spraying rows four to nine reduced spray drift at the 7.6 and $15 \mathrm{~m}$ sampling stations by more than 100-fold compared with spraying the outside three rows (Fig. 2). Similarly a 17-fold reduction was recorded for foliated trees. The quantity of spray drift was much higher (note the difference in the scales between Figs 2 and 3 ) for the dormant application, and drift was likely to contain a higher proportion of larger droplets. This explains the large drop off in drift close to the sprayed block for the dormant application compared with the foliated trial. No agrichemical soil deposits were detected at $180 \mathrm{~m}$ from spraying of the fourth row inwards or at 30,90 or $180 \mathrm{~m}$ from spraying of the tenth row inwards in the full foliage trial.

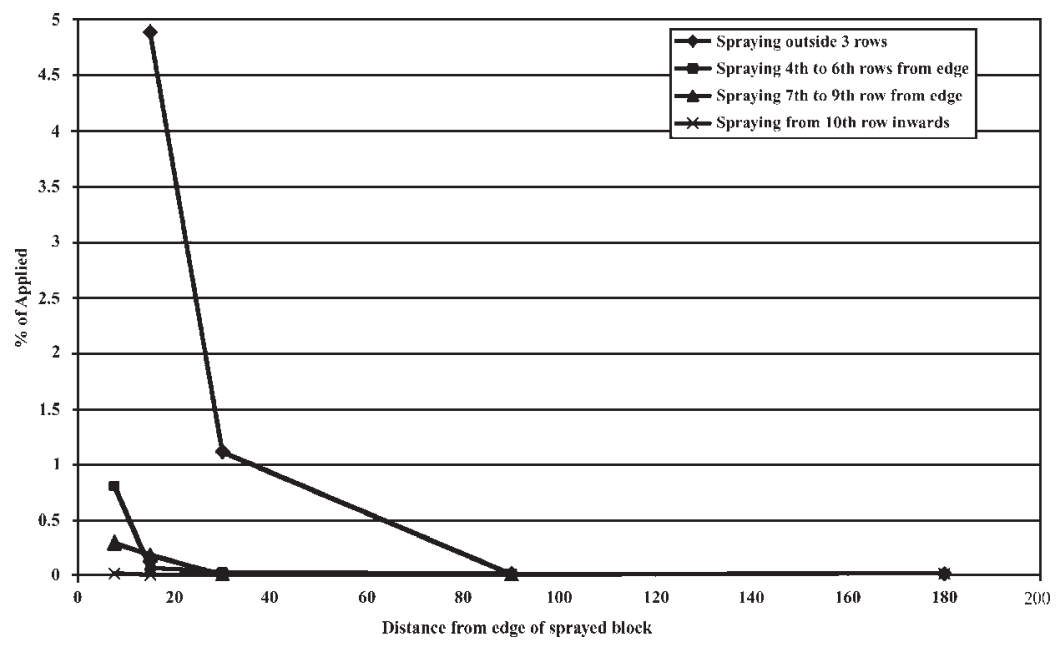

FIGURE 2: Dormant apple orchard trial. Mean proportions of agrichemical detected in samplers at different distances from the sprayed block when the sprayer was operated at different positions in the block. 


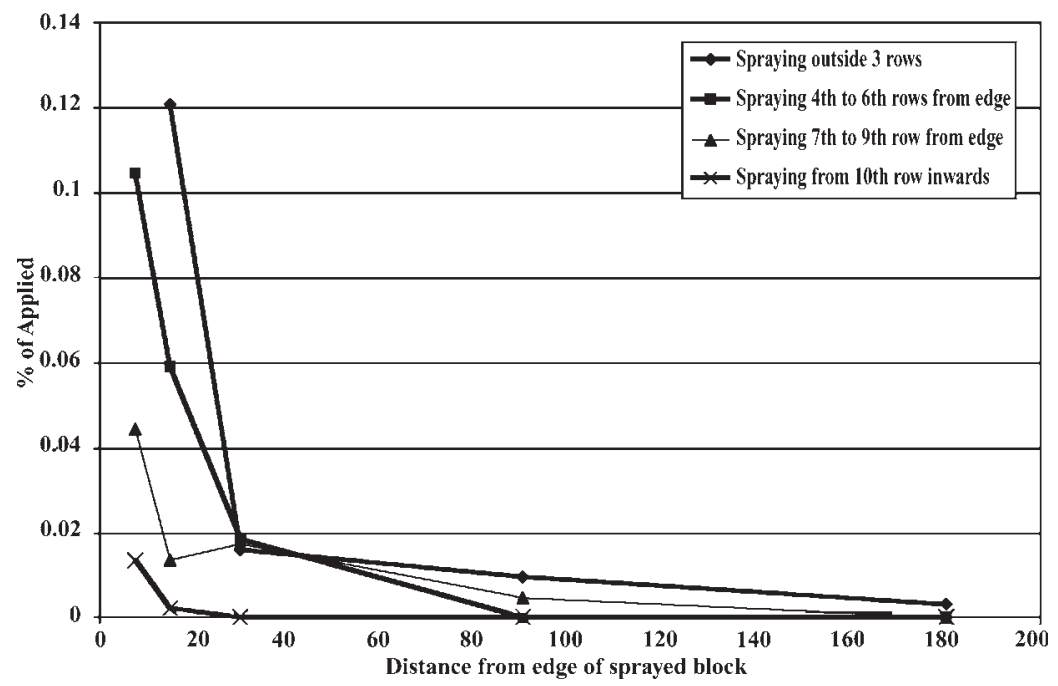

FIGURE 3: Foliated apple orchard trial. Mean proportions of agrichemical detected in samplers at different distances from the sprayed block when the sprayer was operated at different positions in the block.

\section{Aerial drift}

Quantification of aerial drift for the dormant trial was difficult due to the very low level of active ingredient used $(0.068 \mathrm{~kg} / \mathrm{ha}$ myclobutanil $)$ and results were unreliable. Reliable results were recorded for the full foliage trial (Table 4). Airborne drift reduced with distance from the sprayed block in the same manner as soil deposits. The average amount of agrichemical at $30 \mathrm{~m}$ from the sprayed block during the 45 min of spraying was $1.2 \mu \mathrm{g} / \mathrm{m}^{3}$. This was at the low end of the range of aerial drift levels compared with previous trials (Holland et al. 1997).

TABLE 4: Quantity of agrichemical $\left(\mu \mathrm{g} / \mathrm{m}^{3}\right)$ detected in aerial drift samplers at different distances and heights from a sprayed, fully foliated apple orchard block when sprayer was operated at different positions in the block.

\begin{tabular}{lcccc}
\hline & \multicolumn{4}{c}{ Distance $(\mathrm{m})$} \\
Sprayer position & $15(10)$ & $15(2)$ & $30(2)$ & $90(2)$ \\
\hline Spraying rows 1-3 & 1.34 & 2.93 & 1.89 & 0.26 \\
Spraying rows 4-6 & 0.12 & 1.23 & 1.35 & 0 \\
Spraying rows 7-9 & 1.00 & 1.38 & 1.10 & 0.16 \\
Spraying rows 10+ & 0.12 & 0.34 & 0.13 & 0 \\
Total $\left(\mu \mathrm{g} / \mathrm{m}^{3}\right)$ & 2.58 & 5.90 & 4.47 & 0.42 \\
\hline
\end{tabular}

Aerial drift and soil deposits were also monitored after spraying had stopped for both trials. While no drift was detected after spraying had stopped for the dormant trial, diazinon was detected in both soil and air sampling up to an hour after spraying had stopped in the foliated trial (data not shown). This was due to continuing volatilisation of diazinon, which is considerably more volatile than myclobutanil (12 and $0.21 \mathrm{mPa}$ saturated vapour pressure respectively). 


\section{Spray drift modelling}

This trial was carried in a similar fashion to trials in the United States of the Spray Drift Task Force (SDTF), i.e. using actual agrichemicals, large soil deposit samplers and the same station distances, so that the data could be compared. The US data described are the generic orchard curves for the SDTF used in the AgDRIFT ${ }^{\circledR}$ version 1.05 spray drift prediction model (Teske et al. 1997; Teske 1998). Fig. 4 shows the data from our trial in relation to data from US trials. Lower drift levels were recorded for this trial than for the US for the dormant period and similar levels for the full foliage situation. Tree and droplet sizes were similar for the New Zealand and US work but higher wind speeds and sprayer air outputs occurred in the US work, which may account for the higher levels of drift recorded in the US (A. Hewitt, pers. comm.).

Comparison of the Focus Orchard trial data with a New Zealand database of ca 30 spray drift trials found drift levels from the dormant Focus Orchard trial were in excess of those previously recorded while drift levels from the foliated trial were comparable, or lower, than those previously recorded. The other New Zealand trials were conducted in foliated crops with shelter belts, with drift measured beyond the shelter. This comparison highlights the increased spray drift hazard of dormant canopies and unsheltered boundaries.

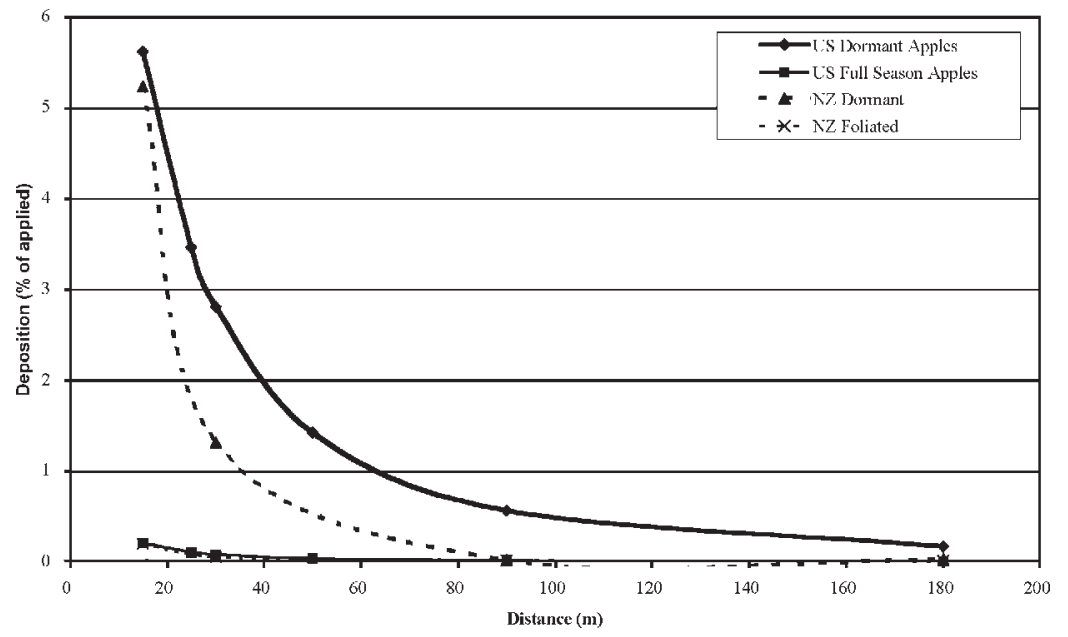

FIGURE 4: Proportions of agrichemical detected at different distances from the sprayed apple blocks that were either dormant or fully foliated in US and NZ trials.

\section{CONCLUSION}

Spraying the outside rows of pipfruit orchards when trees do not have leaves may result in relatively high levels of spray drift downwind from sprayers. Drift levels are significantly reduced in the presence of crop foliage (or shelter) and when sprayers are not operated in close proximity to the orchard boundaries. Orchardists need to identify these potential high drift risk situations for their orchards and manage sprayer operation to minimise spray drift accordingly.

\section{ACKNOWLEDGEMENTS}

This study was funded by Foundation for Research, Science and Technology and ENZA (in support of the Hawke's Bay Focus Orchard). Thanks to Ru and Chan Collins for their co-operation and to Dr Pat Holland of HortResearch, Ruakura. 


\section{REFERENCES}

Holland, P.T., Maber, J.F., May, W.A. and Malcolm, C.P., 1997. Drift from orchard spraying. Proc. 50th N.Z. Plant Prot. Conf: : 112-118.

Johnson, D.R., 1997. A summary of airblast application studies. Spray Drift Task Force, Washington, DC.

Koch, H. and Weisser, P., 2000. Sensor equipped orchard spraying - efficacy, savings and drift reduction. Aspects of Applied Biology, Pesticide Application 57: 357362.

Manktelow, D.W.L. and Praat, J.-P., 1997. The tree-row-volume spraying system and its potential use in New Zealand. Proc. 50th N.Z. Plant Prot. Conf: 119-124.

Perry, P. and Cordero, R., 1995. Sensor controlled orchard sprayers. Proc. National Conference on Pesticide Application Technology: 72-78.

Teske, M.E., 1998. Implementation of the Spray Drift Task Force orchard airblast sprayer data in AgDRIFT® 2.0. Technical Note, Continuum Dynamics Inc, Princeton, New Jersey, USA, No. 98-08.

Teske, M.E., Bird, S.L., Esterly, D.M., Ray, S.L. and Perry, S.G., 1997. A user's guide for AgDRIFT® 1.0. A tiered approach for the assessment of spray drift of pesticides. Technical Note, Continuum Dynamics Inc, Princeton, New Jersey, USA, No. 95-10. 